\title{
Exigências nutricionais de bovinos: uma ferramenta a favor da produtividade
}

Rafaela de Almeida Coutinho ${ }^{1}$, Ana Luiza da Costa Cruz Borges ${ }^{1}$, Juliana Sávia da Silva ${ }^{1}$, Arthur Alves Silva ${ }^{2}$, Frederico Camargos de Souza ${ }^{1}$, Tayane Soares de Abreu ${ }^{2}$, Naiara Barcelos Pereira $^{1}$, Ana Luíza Moreira Silva ${ }^{1}$, Pedro Henrique de Araújo Carvalho ${ }^{1}$, Anna Carolynne Alvim Duque ${ }^{1}$

${ }^{1}$ Universidade Federal de Minas Gerais, Escola de Veterinária, Departamento de Zootecnia, Belo Horizonte, Minas Gerais, Brasil.

${ }^{2}$ FEAD, Belo Horizonte, Minas Gerais, Brasil

*Autor para correspondência, E-mail: rafaelaacoutinho@gmail.com

RESUMO: Objetivou-se com este trabalho fazer uma revisão acerca da importância da determinação das exigências nutricionais de bovinos. As principais exigências a serem determinadas são de proteína, energia e minerais as quais podem ser subdivididas em exigências para mantença e para ganho. A determinação dessas variáveis pode ser feita pelo abate comparativo ou calorimetria animal. No Brasil, a técnica mais amplamente utilizada é o abate comparativo e há apenas dois trabalhos que utilizaram a calorimetria para mensuração de exigências de energia em bovinos. Comparando-se essas duas metodologias, cabe destacar a grande desvantagem do abate comparativo: o elevado custo devido à perda do animal. Apesar do número considerável de trabalhos acerca do tema, ainda são necessários um volume maior de trabalhos com as raças mais utilizadas no Brasil. Além disso, há uma carência de dados de exigências nutricionais determinadas pela técnica da respirometria calorimétrica.

Palavras-chave: abate comparativo, respirometria, ruminantes, zebu

\section{Nutritional requirements of cattle: a tool productivity of favor}

\begin{abstract}
The objective of this study was to conduct a review of the importance of determining the nutritional requirements of cattle. The main requirements to be determined are protein, energy and minerals which can be subdivided into requirements for maintenance and gain. The determination of these variables may be done by comparing the slaughter animal or calorimetry. In Brazil the most widely used technique is the comparative slaughter and only two studies that used calorimetry to measure energy requirements in cattle. Comparing these two methods, it highlights the major drawback of comparative slaughter: the high cost due to the loss of the animal. Despite the considerable number of works on the subject are still needed a higher volume of work with the races most used in Brazil. In addition, there is a lack of data nutritional requirements determined by the technique of calorimetry respirometry.
\end{abstract}

Keywords: comparative slaughter, respirometry, ruminants, zebu

\section{Introdução}

A bovinocultura é uma atividade de grande destaque no cenário do agronegócio nacional e se divide em dois segmentos, destinados à produção de leite e carne. Atualmente, o Brasil possui cerca de 210 milhões de bovinos (IBGE, 2013).
Destes, a grande maioria é criada sob pastejo e constituída por animais zebuínos e seus cruzamentos (Ferraz \& Felício, 2010).

Vale ressaltar ainda, que em um sistema de produção de bovinos o componente de maior custo é a nutrição a qual é determinante para o 
desempenho produtivo dos animais e para a rentabilidade do sistema de produção (Silva et al., 2010).

De acordo com (Véras et al., 2000) a maioria das rações para ruminantes são balanceadas a partir de tabelas elaboradas em países onde as condições ambientais, alimentos e animais são diferentes das condições brasileiras. Nesse sentido, a determinação das exigências nutricionais de bovinos, mais especificamente dos animais zebuínos e seus cruzamentos, constitui-se em uma ferramenta relevante para obtenção de melhores desempenhos produtivos do rebanho brasileiro.

Objetivou-se com este trabalho fazer uma revisão acerca da importância da determinação de exigências nutricionais de bovinos.

\section{Revisão}

As principais exigências a serem determinadas são energia, proteína e minerais. Este último componente, embora presente em menores proporções tem importância vital. De acordo com (Berchielli et al., 2011) a energia não é considerada um nutriente, ela é liberada a partir da oxidação dos constituintes orgânicos da dieta e é utilizada pelo animal para realização de trabalho ou produção de calor. Ainda de acordo com este mesmo autor, as proteínas são macromoléculas presentes nas células como componentes estruturais, além de apresentarem funções enzimáticas, hormonais, recepção de estímulos hormonais e armazenamento de informações genéticas.

As exigências de energia, proteína e minerais são divididas basicamente em exigência para mantença e para ganho (NRC, 2000). A primeira é requerida para atender os processos metabólicos essenciais à vida, enquanto a segunda é requerida para a produção.

A oferta de nutrientes além dos requisitos dos animais pode acarretar em transtornos metabólicos e elevar o custo de produção, no entanto a deficiência de qualquer nutriente determinaria queda na produção. Nesse sentido Leonel et al. (2006) destacam a necessidade de se conhecer com mais exatidão as exigências nutricionais em energia, proteína, minerais e vitaminas para alcançar a sustentabilidade da atividade.

Somente o conhecimento das exigências nutricionais dos bovinos não é suficiente para um bom desempenho produtivo. São necessárias também maiores informações acerca do valor nutricional e composição dos alimentos que são mais comumente utilizados nos sistemas de produção brasileiros. Tendo em vista o pequeno volume de trabalhos com essas informações no Brasil (Valadares Filho, 2006) vêm desenvolvendo tabelas com a composição de alimentos utilizados com maior frequência nas condições brasileiras.

\section{Metodologias para determinação das exigências}

Entre os métodos utilizados para determinação de exigências nutricionais destacam-se a calorimetria animal e o abate comparativo. De acordo com Posada et al. (2011) na calorimetria direta o calor desprendido pelo animal é medido pelo aumento de temperatura de um volume conhecido de água ou por meio de corrente elétrica, enquanto na calorimetria indireta o calor é obtido a partir das quantidades de gás carbônico produzido e do oxigênio consumido. Nesse método a energia retida será determinada pela diferença entre o consumo de energia metabolizável e a produção de calor. No método do abate comparativo a energia retida no animal é determinada diretamente e a produção de calor é obtida a partir da diferença entre o consumo de energia metabolizável e a energia retida.

A técnica do abate comparativo além de permitir quantificar a produção de calor indiretamente e a energia retida diretamente, permite determinar a composição dos principais componentes químicos do corpo: água, gordura, proteína e minerais. Ribeiro (2009) ressalta a importância da composição corporal para estimar as exigências nutricionais. Essa composição sofre influência de fatores como idade, raça e sexo. De maneira geral, primeiramente há o crescimento do tecido ósseo, em seguida do tecido muscular e por fim do tecido adiposo. Dessa forma com o avançar da idade há aumentos nas proporções de gordura enquanto ocorre o decréscimo nas proporções de água e proteínas. Os animais mais jovens são mais ricos em água e mais pobres em gorduras e as concentrações de proteínas, cinzas e água diminuem com a idade e a engorda.

Ribeiro (2009) descreveu a metodologia clássica desenvolvida por Hankins \& Howe (1946) para determinar a composição química corporal através da utilização de amostras da 
carcaça entre a $9^{\mathrm{a}}$ e $11^{\mathrm{a}}$ costelas. Nessa metodologia utiliza-se a meia carcaça direita a qual é resfriada e posteriormente é feita a separação da carcaça entre a $12^{\mathrm{a}}$ e $13^{\mathrm{a}}$ costelas. Em seguida é retirado o corte da 9-10-11 ${ }^{\text {a }}$ costelas. O corte é pesado e separado fisicamente em músculo, gordura e ossos os quais são pesados separadamente para a determinação da composição física do corte. Posteriormente esses componentes são congelados, moídos conjuntamente, homogeneizados e retiram-se amostras para posteriores análises químicas. Comparando-se essas duas metodologias utilizadas para determinação de exigências é importante ressaltar que o abate comparativo tem como grande desvantagem o elevado custo devido à perda do animal. Nesse sentido a calorimetria seria uma alternativa bastante interessante uma vez que não é necessário abater o animal e este poderá ser utilizado para outros estudos ou até mesmo para fins produtivos. Apesar dessas desvantagens do abate comparativo, Posada et al. (2011) ressaltam que essa técnica pode ser realizada em condições mais parecidas com as condições mais comumente encontradas a campo, enquanto a técnica calorimétrica tem como limitação ajustar os resultados obtidos em condições laboratoriais a situações encontradas na prática.

Silva (2011) foi pioneiro na determinação de exigências nutricionais de energia de bovinos por meio da respirometria calorimétrica no Brasil. Esse autor utilizou 18 fêmeas bovinas em crescimento as quais apresentavam peso vivo inicial médio de $240 \mathrm{~kg}$. Os animais pertenciam a três diferentes grupos raciais com potencial leiteiro: Gir, Holandês e F1 Holandês x Gir. A dieta oferecida aos animais proporcionava ganhos leves para que dessa forma fossem mensuradas as exigências de energia líquida para mantença dos animais. As fêmeas Gir apresentaram menor exigência de energia líquida para mantença $(85,2$ $\mathrm{kcal} / \mathrm{PV}^{0,75}$ ) enquanto que as fêmeas F1 apresentam maior exigência $\left(102,3 \mathrm{kcal} / \mathrm{PV}^{0,75}\right)$. As fêmeas holandesas apresentaram valores intermediários $\left(96,4 \mathrm{kcal} / \mathrm{PV}^{0,75}\right)$.

Lage (2011), trabalho não publicado, utilizou a técnica da respirometria calorimétrica para a determinação de exigências de energia para mantença de fêmeas de dois grupos raciais com potencial leiteiro: Gir e F1 Holandês x Gir. Nesse trabalho não foram observadas diferenças estatísticas nos valores de exigência de energia líquida para mantença entre os dois grupos raciais sendo que o valor médio encontrado foi de 84,43 $\mathrm{kcal} / \mathrm{PV}^{0,75}$. A autora ressalta a proximidade desse valor com o que foi proposto pelo NRC (2001) de $80 \mathrm{kcal} / \mathrm{PV}^{0,75}$ para animais com potencial leiteiro.

Marcondes et al. (2009) determinaram as exigências nutricionais de energia, proteína e macro minerais de bovinos nelores de três diferentes classes sexuais (machos não castrados, machos castrados e fêmeas) por meio da técnica de abate comparativo. $\mathrm{O}$ autor observou que os machos castrados foram $23 \%$ mais exigentes que os não castrados e $11 \%$ menos exigentes que as fêmeas. $O$ autor destaca a diferença desses valores em relação ao que é preconizado pelo NRC (2000): machos castrados são $18 \%$ mais exigentes que os não castrados e $18 \%$ menos exigentes que as fêmeas em relação às exigências líquidas de energia para ganho de peso. Em relação às exigências de minerais, os valores encontrados foram bem próximos aos valores descritos na literatura. No que se refere à concentração de proteína, o autor observou decréscimo nessas concentrações com a elevação do peso dos animais.

Paulino et al. (1999) avaliaram a composição corporal e as exigências macro minerais $(\mathrm{Ca}, \mathrm{P}$, $\mathrm{Mg}$, Na e K) para ganho de peso de bovinos não castrados de quatro raças zebuínas: Gir, Guzerá, Mocho-Tabapuã e Nelore em confinamento. Nesse trabalho, as raças utilizadas não diferiram entre si quanto à composição corporal de macro elementos a qual se mostrou decrescente com a elevação do peso corporal. $\mathrm{O}$ autor destaca a diferença nos requisitos de $\mathrm{Ca}, \mathrm{P}, \mathrm{Mg}, \mathrm{Na}$ e $\mathrm{K}$ para ganho de peso dos animais comparando-se a dados de sistemas consagrados como o ARC (1980) e AFRC (1991) os quais apresentam valores de exigências superiores ao encontrado nesse trabalho. Rabelo et al. (2007) também avaliaram a composição corporal e exigências líquidas e dietéticas de $\mathrm{Ca}, \mathrm{P}, \mathrm{Mg}, \mathrm{Na}$ e $\mathrm{K}$, no entanto trabalhando com novilhas da raça Guzerá e Holandesa em fase de crescimento. Os autores também observaram uma diminuição na concentração desses macros minerais com a elevação do peso corporal e não foi observada diferença entre as raças quanto às exigências desses elementos.

Outros autores também avaliaram as exigências nutricionais e composição corporal de bovinos por meio da técnica de abate comparativo. Freitas et al. (2006) avaliaram as 
exigências de energia e proteína para ganho de peso em bovinos Nelore puros e mestiços (Nelore, F1 Nelore x Angus, F1 Nelore x PardoSuíço e F1 Nelore x Simental) submetidos a dietas com diferentes níveis de concentrado (30, 40,60 e $70 \%$ ).

Ribeiro (2009) utilizou tourinhos da raça Santa Gertrudes para avaliar o efeito da substituição parcial da fração protéica do concentrado por subproduto da produção de lisina sobre a composição corporal e exigências nutricionais.

\section{Conclusão}

Apesar do número considerável de trabalhos de determinação de exigências nutricionais de bovinos no Brasil, ainda é necessário um volume maior de trabalhos acerca do tema utilizando as raças mais difundidas na pecuária brasileira.

Vale ressaltar a necessidade de elaboração de trabalhos de determinação de exigências a partir da calorimetria animal (indireta), respirometria, já que esta possibilita a utilização do mesmo animal por diversas vezes, invés de abatê-lo.

\section{Referências bibliográficas}

Berchielli, T. T., Pires, A. V. \& Oliveira, S. G. 2011. Nutrição de Ruminantes. 2th ed. FUNEP, Jaboticabal, Brazil.

Ferraz, J. B. S. \& Felício, P. E. 2010. Production systems - An example from Brazil. Meat Science, 84, 238-243.

Freitas, J. A., Queiroz, A. C., Dutra, A. R., Vieira, R. A. M., Lana, R. P., Leonel, F. d. P., Henrique, D. S., Lima, A. V. \& Souza, J. C. 2006. Composição do ganho e exigências de energia e proteína para ganho de peso em bovinos Nelore puros e mestiços. Revista Brasileira de Zootecnia, 35.

Hankins, O. G. \& Howe, P. E. 1946. Estimation of the composition of beef carcasses and cuts. US Department of Agriculture, 926, 1-20.

IBGE. 2013. Contas nacionais trimestrais. Jul.set. 2013. 20th ed. Available in: www.ibge.gov.br, Rio de Janeiro, BR.

Lage, H. F. A. Partição da energia e exigência de energia líquida para mantença de novilhas Gir e F1 Holandês x Gir. 2011. 78f. Dissertação (Mestrado em Zootecnia) - Universidade Federal de Minas Gerais, Escola de
Veterinária, Programa de Pós-Graduação em Zootecnia, Belo Horizonte.

Leonel, F. P., Pereira, J. C., Vieira, R. A. M., Freitas, J. A., Dutra, A. R., Lima, A. V., Divino, M. \& Ribeiro, M. G. C. 2006. Exigências nutricionais em macronutrientes minerais (Ca, $\mathrm{P}, \mathrm{Mg}$, $\mathrm{Na}$ e $\mathrm{K}$ ) para novilhos de diferentes grupos genéticos. Revista Brasileira de Zootecnia, 35, 584-590.

Marcondes, M. I., Valadares Filho, S. d. C., Paulino, P. V. R., Valadares, R. F. D., Paulino, M. F., Nascimento, F. B. \& Fonseca, M. A. 2009. Exigências nutricionais de proteína, energia e macrominerais de bovinos Nelore de três classes sexuais. Revista Brasileira de Zootecnia, 38, 1587-1596.

NRC. 2000. Nutrient Requirements of Beef Cattle, 7th rev. edn. Natl. Acad. Press, Washington, DC, USA.

NRC. 2001. Nutrient Requirements of Dairy Cattle, 7th rev. edn. Natl. Acad. Press, Washington, DC.

Paulino, M. F., Fontes, C. A. A., Jorge, A. M., Queiroz, A. C., Silva, J. F. C. \& Gomes Junior, P. 1999. Composição corporal e exigências de macroelementos minerais $(\mathrm{Ca}$, $\mathrm{P}, \mathrm{Mg}, \mathrm{Na}$ e $\mathrm{K}$ ) de bovinos não-castrados de quatro raças zebuínas. Revista Brasileira de Zootecnia, 28, 634-641.

Posada, S. L., Noguera, R. R., Rodríguez, N. M., Borges, A. L. \& Reis, R. 2011. Energy requirements for beef cattle: concepts and experimental results in tropical conditions. Revista Colombiana de Ciencias Pecuarias, 24, 617-622.

Rabelo, L. S., Borges, A. L. C., Gonçalves, L. C., Machado, G. S., Delgado, L. P., Ferreira, J. J., Borges, I., Rodriguez, N. M., Graça, D. S. \& Saliba, E. O. 2007. Composição corporal e exigências nutricionais de macrominerais para novilhas em crescimento das raças Guzerá e Holandesa. Arquivo Brasileiro de Medicina Veterinaria e Zootecnia, 59, 395-405.

Ribeiro, G. M. 2009. Composição corporal e exigências nutricionais de energia e proteína de tourinhos Santa Gertrudes confinados, recebendo alto concentrado e subproduto da produção de lisina. Departamento de Zootecnia. Universidade Estadual Paulista, Faculdade de Ciências Agrárias e Veterinárias, Jaboticabal. 
Silva, R. R., Prado, I. N., Carvalho, G. G. P., Silva, F. F., Almeida, V. V. S., Santana Júnior, H. A., Paixão, M. L. \& Abreu Filho, G. 2010. Níveis de suplementação na terminação de novilhos Nelore em pastagens: aspectos econômicos. Revista Brasileira de Zootecnia, 39, 2091-2097.

Silva, R. R.. Resipirometria e determinação das exigências de energia e produção de metano de fêmeas bovinas leiteiras de diferentes genótipos. 2011. 61f. Tese (Doutorado) Universidade Federal de Minas Gerais, Escola de Veterinária, Belo Horizonte.

Valadares Filho, S. C. 2006. Tabelas brasileiras de composição de alimentos para bovinos. UFV, Viçosa.

Véras, A. S. C., Valadares Filho, S. C. \& Coelho da Silva, J. 2000. Composição corporal e requisitos energéticos e protéicos de bovinos Nelore, não-castrados, alimentados com rações contendo diferentes níveis de concentrado. Revista Brasileira de Zootecnia, 29, 2379-2389.

Recebido em Maio 29, 2015

Aceito em Julho 4, 2015

License information: This is an open-access article distributed under the terms of the Creative Commons Attribution License, which permits unrestricted use, distribution, and reproduction in any medium, provided the original work is properly cited. 